\title{
Effects of solar wind density on auroral electrojets and brightness under influence of substorms
}

\author{
J.-H. Shue ${ }^{1}$, Y. Kamide ${ }^{2}$, and J. W. Gjerloev ${ }^{3}$ \\ ${ }^{1}$ Institute of Space Science, National Central University, Jhongli City, Taoyuan County 32001, Taiwan \\ ${ }^{2}$ Research Institute for Sustainable Humanosphere, Kyoto University, Uji 611-0011, Japan \\ ${ }^{3}$ Applied Physics Laboratory, Johns Hopkins University, 11100 Johns Hopkins Road, Laurel 20723-6099, USA
}

Received: 27 August 2008 - Revised: 2 December 2008 - Accepted: 2 December 2008 - Published: 6 January 2009

\begin{abstract}
Using the auroral electrojet indices and Polar Ultraviolet Imager auroral images, we examined two fortuitous events during which the solar wind density had clear enhancements while the other solar wind parameters were relatively constant. Two electrojet enhancements were found in each event. The first electrojet enhancement was likely to be related to a substorm in which an auroral bulge appeared at premidnight. The second electrojet enhancement was driven by the density enhancement in the solar wind. The auroral oval became wider in latitude and the auroral distribution became dispersed after the density enhancement arrived at the Earth. The total auroral power integrated over the entire nightside region from 50 to $80^{\circ}$ MLAT, however, did not increase significantly in response to the density enhancement. Our interpretation is that the substorm that occurred prior to the solar wind density enhancement had drained out a significant portion of the stored energy in the magnetotail; therefore, less precipitation energy was deposited into the auroral ionosphere by the density enhancement.
\end{abstract}

Keywords. Magnetospheric physics (Auroral phenomena; Current systems; Solar wind-magnetosphere interactions)

\section{Introduction}

The westward auroral electrojet is enhanced on the dawnside when the interplanetary magnetic field (IMF) is southward. A substorm adds an additional westward auroral electrojet on the nightside. The maximum intensity of the westward auroral electrojet, which is commonly monitored by the $A L$ index, can also be enhanced by a solar wind density $\left(N_{p}\right)$ enhancement (Burch, 1972; Iijima, 1973; Kokubun et al., 1977;

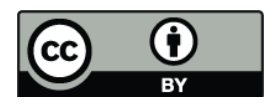

Correspondence to: J.-H. Shue

(jhshue@jupiter.ss.ncu.edu.tw)
Kamide et al., 1998; Shue and Kamide, 1998, 2001, 2005; Zesta et al., 2000; Liou et al., 2004). It was found that a $N_{p}$ enhancement creates higher auroral electrojets during periods of southward IMF than during periods of northward IMF (Zesta et al., 2000; Shue and Kamide, 2001, 2005).

A westward electrojet enhanced by a solar wind density enhancement could be due to an enhanced electric field (Hairston et al., 1999; Lukianova, 2003; Lopez et al., 2004; Ober et al., 2006) and/or an enhanced conductivity related to an enhanced auroral brightness (Craven et al., 1986; Brittnacher et al., 2000; Chua et al., 2001; Zhou and Tsurutani, 2001; Shue et al., 2002; Boudouridis et al., 2003). Chua et al. (2001) concluded that the electron precipitation was less structured in spatial scale and had higher fluxes of lowerenergy precipitating electrons $(\leq 7 \mathrm{keV})$ for aurora caused by a pressure pulse than that for aurora caused by an isolated substorm expansion onset. Boudouridis et al. (2003) reported an increase in the energy flux of precipitating particles in response to a pressure pulse.

Polar Ultraviolet Imager (UVI) auroral images provide us with unprecedented details about the development of aurora in both the temporal and spatial resolutions (Torr et al., 1995). Previous studies reported the existence of a significant enhancement in auroral brightness by a solar wind density enhancement for southward IMF. In the present study we use Polar UVI auroral images and the $A E$ indices to study two fortuitous events in which there were clear density enhancements while the other solar wind parameters were relatively constant. Accidentally, a substorm bulge occurred before the major density enhancement had an effect on the ionosphere, which can be seen from Polar UVI images. With these two events, we can examine effects of the solar wind density on auroral electrojets and brightness under the influence of substorms.

Published by Copernicus Publications on behalf of the European Geosciences Union. 

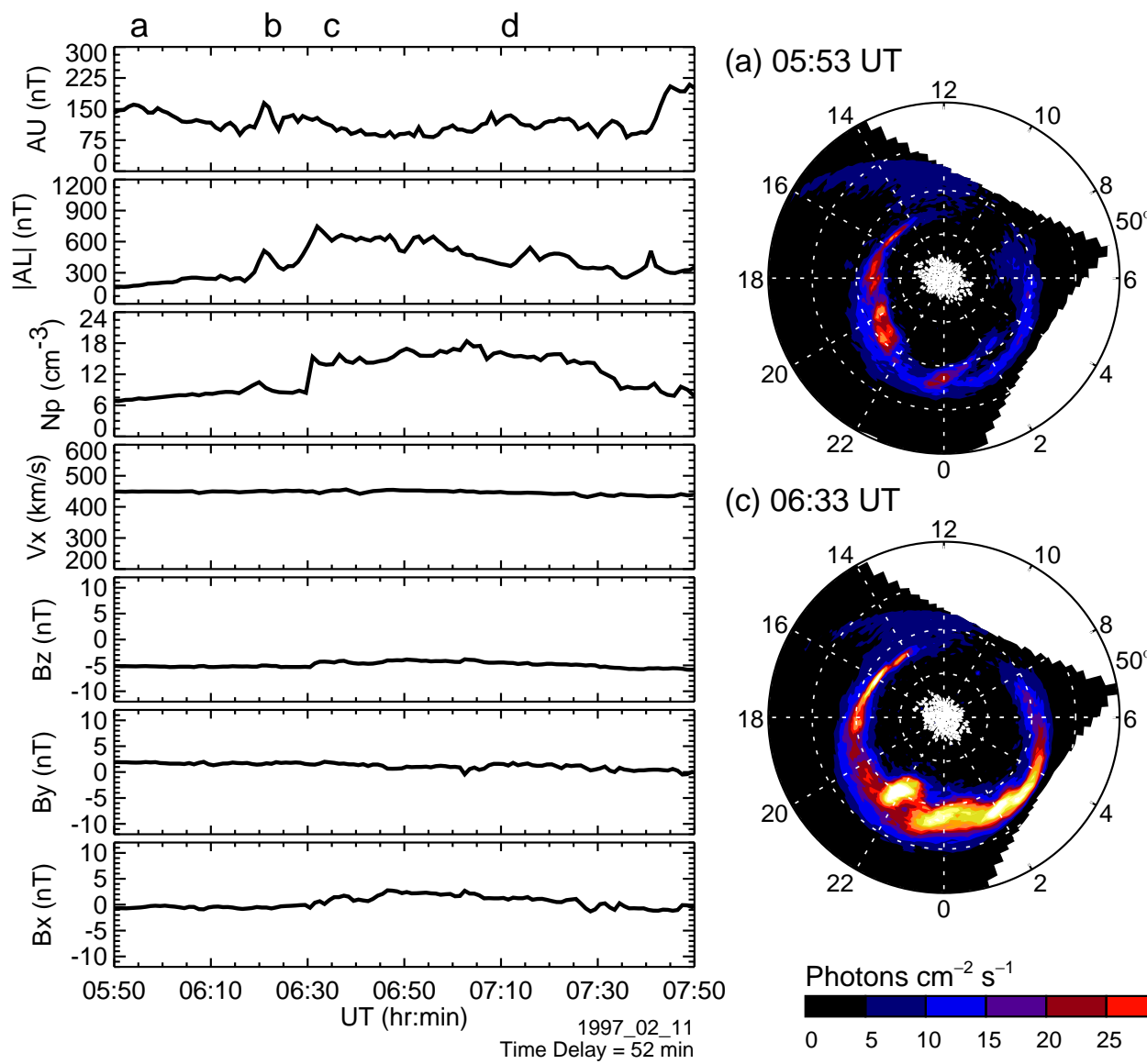

(b) 06:20 UT

(c) 06:33 UT

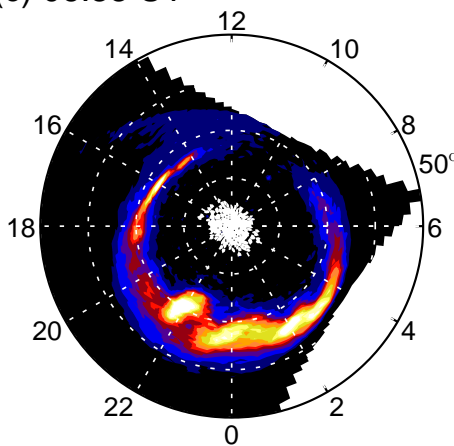

(d) 07:09 UT

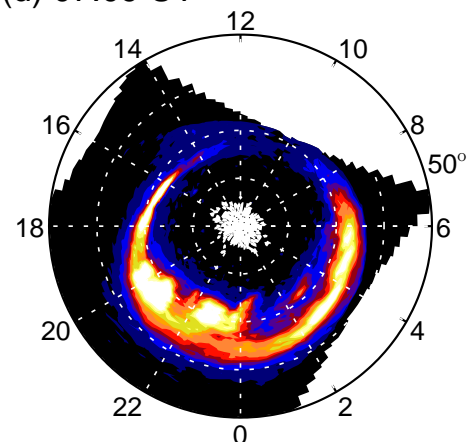

Photons $\mathrm{cm}^{-2} \mathrm{~s}^{-1}$

Fig. 1. The $A U$ and $|A L|$ indices, solar wind measurements from the Wind satellite and auroral images from Polar Ultraviolet Imager (UVI) during the period of 05:50-07:50 UT, 11 February 1997. The solar wind density, $N_{p}$, the $X$ component of the solar wind velocity, $V_{x}$, and the three components of the interplanetary magnetic field, $B_{x}, B_{y}$, and $B_{z}$, have been shifted by 52 min. We have selected four Polar UVI images that are suitable to show the development of the aurora in response to the $N_{p}$ enhancement. The corresponding electrojet and solar wind conditions for the four images are referred to as the labels a-d on the top of the $A U$ panel.

\section{Data}

In this study we used 3-min resolution Polar UVI images at the $160-180 \mathrm{~nm} \mathrm{~N}_{2}$ Lyman-Birge-Hopfield emission band, known as the LBH-long band, in units of photons $\mathrm{cm}^{-2} \mathrm{~s}^{-1}$. The intensity of this band is approximately proportional to the energy flux of precipitating electrons (Germany et al., 1990, 1994; Strickland et al., 1993). We then used a conversion factor $\left(1\right.$ photon $\left.\mathrm{cm}^{-2} \mathrm{~s}^{-1}=0.27 \mathrm{ergs} \mathrm{cm}^{-2} \mathrm{~s}^{-1}\right)$ to convert the auroral brightness to energy flux (Brittnacher et al., 1997). To quantitatively evaluate the development of nightside aurora during the events, we integrated all energy fluxes over the entire nightside region from 50 to $80^{\circ}$ MLAT.

The $A U$ and $A L$ indices used here were from the SuperMAG database (Gjerloev et al., 2004). Wind plasma (Ogilvie et al., 1995) and magnetic fields (Lepping et al., 1995) in Geocentric Solar Magnetospheric (GSM) coordinates were used to identify the density enhancements and the variations of the IMF.

\section{Results}

In this section we will present the two events of the westward auroral electrojet enhancements during which only a major density enhancement occurred while the other solar wind parameters were relatively unchanged. One event occurred during the period of 05:50-07:50 UT, 11 February 1997 and the other occurred during the period of 10:20-12:20 UT, 10 January 1997. Undoubtedly, the two events are quite useful to study the density effect on the westward electrojet because the density effect can be isolated from the effects of the other solar wind parameters.

\subsection{The first event: 11 February 1997}

The solar wind density had two enhancements $\left(2 \mathrm{~cm}^{-3}\right.$ and $7 \mathrm{~cm}^{-3}$ ) during the period of 05:50-07:50 UT on 11 February 1997, as shown in Fig. 1. The other solar wind parameters, $V_{x}, B_{z}, B_{y}$, and $B_{x}$, were, evidently, nearly constant. There 
were two peaks in $|A L|$ in association with the two enhancements in $N_{p}$. The strength of the first peak is $510 \mathrm{nT}$ while the strength of the second peak is $740 \mathrm{nT}$. We have selected four Polar UVI auroral images for a demonstration of the event. Panel (a) was taken prior to the density enhancements. We chose the first image after each density enhancement for panels (b) and (c). There was an apparent substorm bulge occurred at premidnight on panel (b). The auroral distribution became dispersed on panel (c). Panel (d) was taken after the two density enhancements. The solar wind data have been shifted by $52 \mathrm{~min}$ to match the two peaks in $N_{p}$ and $|A L|$.

For this event, the propagation time estimated by the distance between Wind and the center of the earth divided by the solar wind propagation speed is $48 \mathrm{~min}$. However, the uncertainty in estimating the propagation time by this ballistic method for an event is usually large (Ridley, 2000). Therefore, in this study, we match the density enhancements to the enhancements in $|A L|$. We believe that this is the best practical way to estimate the propagation time for events in which the enhancements in both the solar wind and ionosphere were observed. Note that the propagation time estimated by the ballistic method (48 $\mathrm{min}$ ) is at the right order of magnitude in comparison to that estimated by the "matching" method (52 min).

The magnitude of the first (second) enhancement was $2 \mathrm{~cm}^{-3}\left(7 \mathrm{~cm}^{-3}\right)$, but its associated increase in $|A L|$ was $294 \mathrm{nT}(373 \mathrm{nT})$. This means that the weaker density enhancement creates a higher rate of change of $|A L|$ per unit of $N_{p}$. We speculate that another process, such as a substorm, is involved in the $|A L|$ enhancement in addition to the external density effect. Although the first density enhancement is considered as small in terms of its magnitude, it may serve as a trigger of substorm activities if sufficient energy has already been stored in the magnetotail (Lee et al., 2007), for example, IMF $B_{z}$ is negative for a long period prior to the density enhancement.

The first panel in Fig. 2 shows the variations of the auroral power during the event. It is found that the values of the power for panels (b) and (c) are almost the same, indicating that the second density enhancement did not significantly increase the auroral power. The shaded area denotes the period during the major density enhancement. The auroral power increased its strength gradually. This result is different from the results of past studies (e.g. Zhou and Tsurutani, 2001; Shue et al., 2002), which showed that a solar wind density significantly enhances auroral intensity during a period of southward IMF.

\subsection{The second event: 10 January 1997}

There was a $13 \mathrm{~cm}^{-3}$ density enhancement during the period of 10:20-12:20 UT, 10 January 1997, as shown in Fig. 3. The other solar wind parameters were relatively constant. The eastward electrojet, monitored by the $A U$ index, also had an enhancement in response to the density enhancement

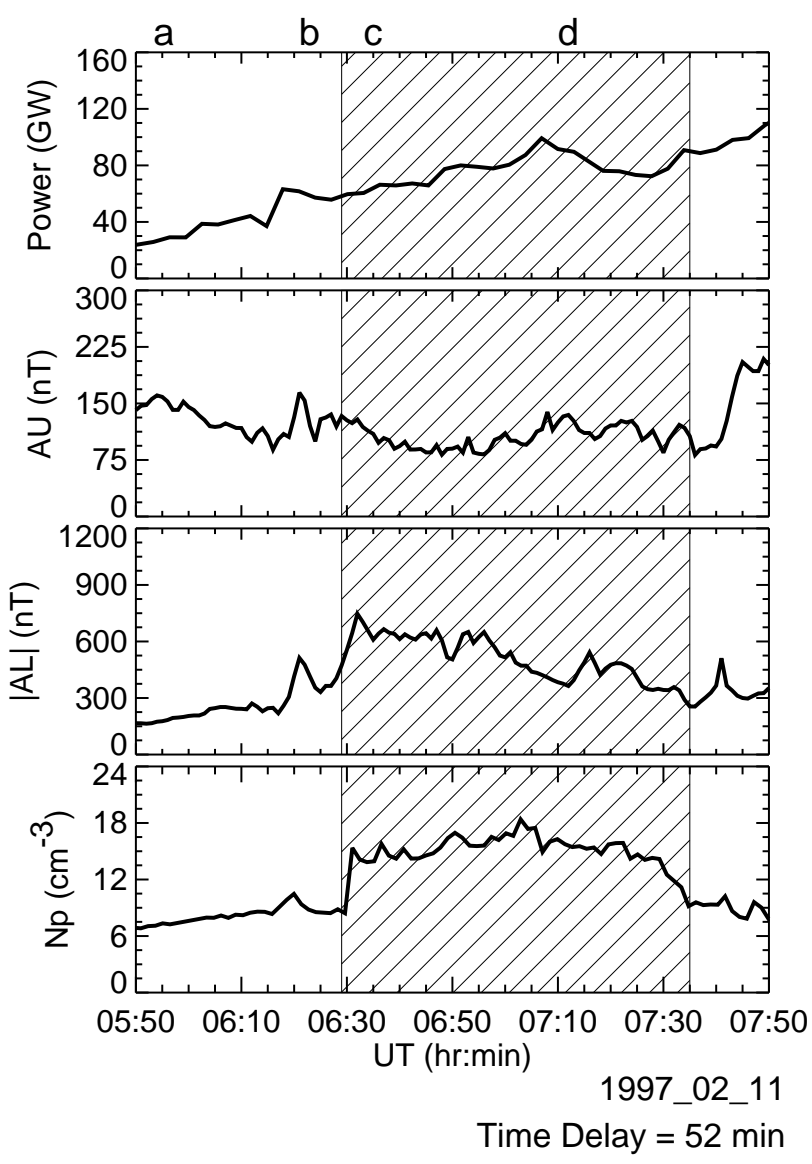

Fig. 2. Variations of the $A U$ and $|A L|$ indices, the solar wind density, $N_{p}$, and the auroral power during the period of 05:5007:50 UT, 11 February 1997. The shaded area indicates the period of the major density enhancement. The labels a-d on the top of the power panel are referred to the auroral images shown in Fig. 1.

(Kamide et al., 1998). The solar wind data have been shifted by $25 \mathrm{~min}$ to match this $A U$ enhancement with the density enhancement. Note that the propagation time of the solar wind estimated by the ballistic method is $21 \mathrm{~min}$. Two enhancements are found in $|A L|$. The first one occurred prior to the density enhancement. Panel (b) shows an auroral bulge at premidnight. Kamide et al. (1998) interpreted this auroral activity as an internally triggered substorm. The second one was related to the density enhancement. The auroral oval became wider in latitude (Kamide et al., 1998; Boudouridis et al., 2003) and the auroral distribution became dispersed (Kamide et al., 1998; Chua et al., 2001) in response to the density enhancement, as shown in panel (c). Panel (d) was taken after the density enhancement.

We also calculated the auroral power for the 10 January 1997 event, as shown in the first panel of Fig. 4. The shaded area is used to denote the period of the density enhancement. Contrary to results by previous studies (e.g. Zhou and Tsuru- 

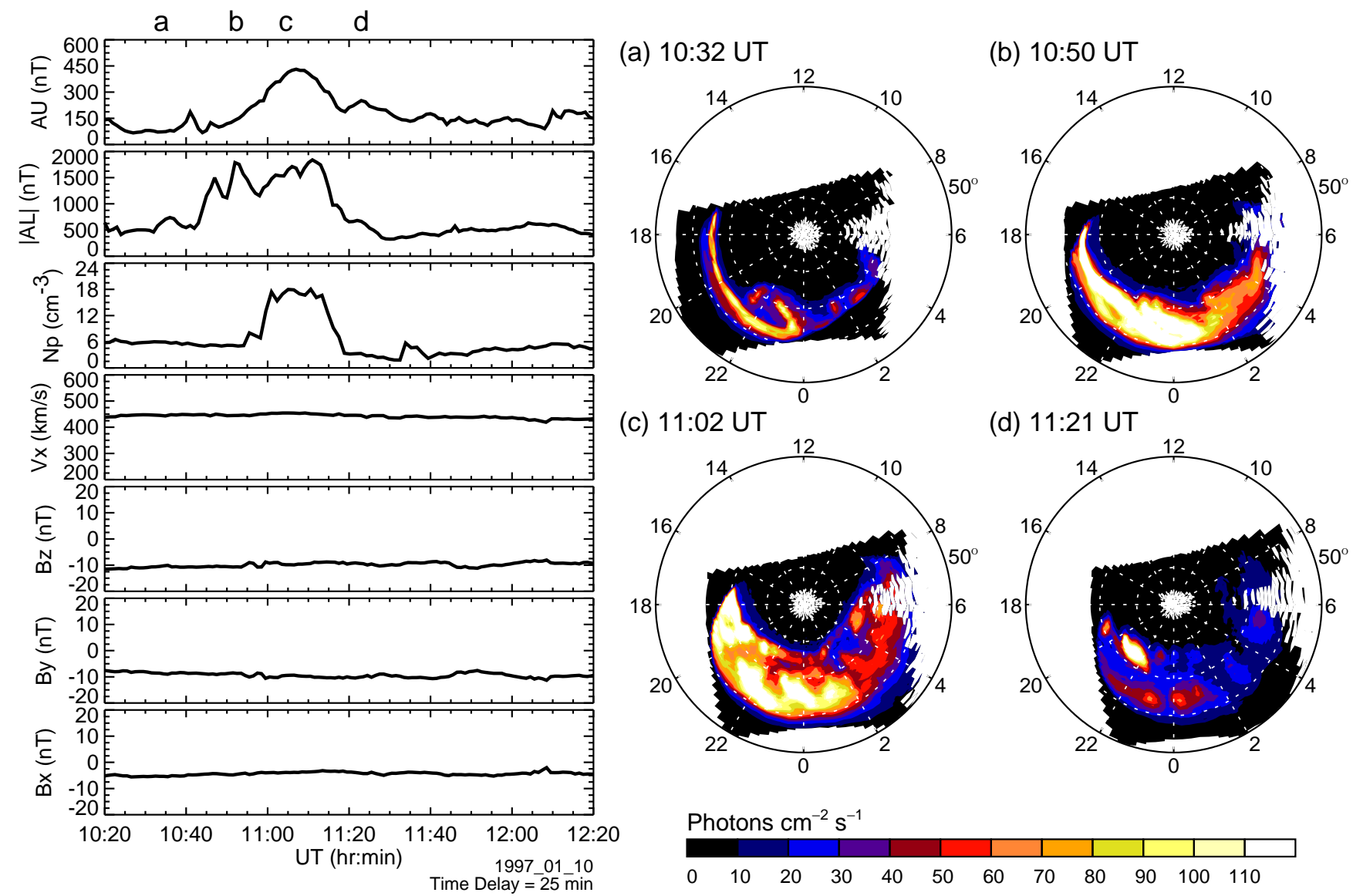

(c) 11:02 UT

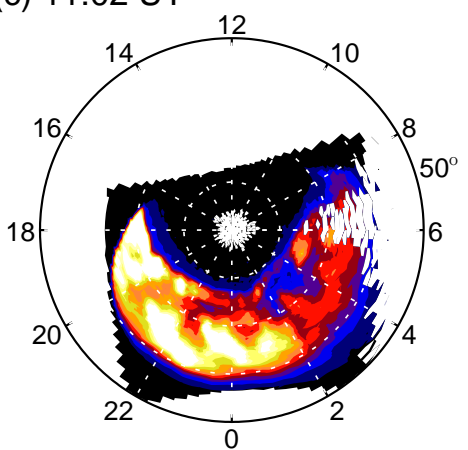

(d) 11:21 UT

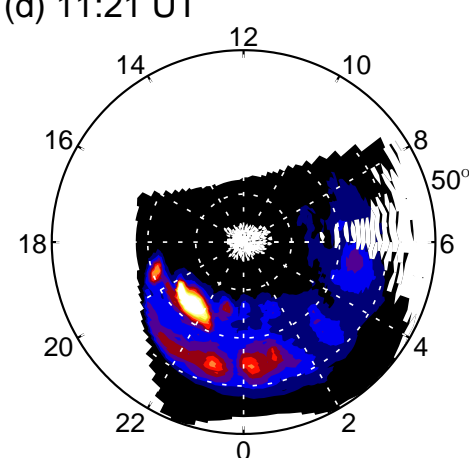

Photons $\mathrm{cm}^{-2} \mathrm{~s}^{-1}$

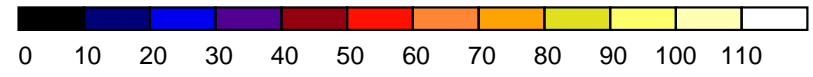

Fig. 3. The format is the same as Fig. 1 except for the 10 January 1997 event and the shifted time of 25 min in the solar wind parameters.

tani, 2001; Shue et al., 2002), the auroral power was decreasing during the density enhancement. The $|A L|$ index significantly increased in response to the density enhancement. Note that the previous studies did not consider the density effect "under the influence of substorms."

\section{Discussion and conclusions}

We studied two fortuitous events during which only the solar wind density had clear variations. One major solar wind density enhancement and two westward electrojet enhancements were observed during each of the two events. Accidentally, a substorm that occurred before the density enhancement affected the auroral ionosphere, resulting in the first westward electrojet enhancement for each event.

The causes of the substorm that occurred before the major density enhancement are still unknown. It could be internally triggered during a period of southward IMF (Horwitz, 1985), externally triggered by a northward turning of the IMF (Caan et al., 1977; Lyons, 1995), or by a solar wind pressure enhancement (e.g. Lee et al., 2007). The three components of the IMF for the two events were relatively constant. Therefore, the chance of substorm triggered by the northward turning is very small. For the 11 February 1997 event, the substorm could be triggered by the internal process, or the small density enhancement. The substorm for the 10 January 1997 event was most likely related to the internal process because of no other possible factors responsible for the trigger of the substorm.

A density enhancement not only can increase the strength of the auroral electrojet, but also can increase the latitudinal width of the auroral oval (e.g. Boudouridis et al., 2003). The density enhancement in the second event significantly increased the latitudinal width of the auroral oval, but the second density enhancement in the first event did not. By examining the strength of these two density enhancements, the second event is $6 \mathrm{~cm}^{-3}$ larger than the first event. From these observations one may conclude that the larger strength of a density enhancement results in a wider auroral oval. However, this conclusion of how the size of the auroral oval responds to a solar wind density enhancement may be oversimplified. One thing that should not be ignored is that IMF $B_{z}$ is a very important parameter to control the energy deposit into 
the auroral ionosphere through the solar wind density effect. The southward component of IMF $B_{z}$ for the second event $(-10 \mathrm{nT})$ is twice larger than that for the first event $(-5 \mathrm{nT})$. We believe that this larger southward component also contributes to the wider auroral oval for the second event.

Ohm's law can be used to interpret the electrodynamics of the auroral ionosphere during the two events. From the law, the electric field is equal to a ratio of the electric currents to the ionospheric conductance. It can be assumed in the first approximation that $|A L|$ represents the overall electric currents. The auroral brightness can represent the conductance under an assumption of the proportionality between the auroral brightness and the conductance. It should be noted that this assumption may have been simplified. An increase in the ratio, i.e. $|A L|$ to the auroral brightness, indicates an increase in the electric field. In our events, the auroral power did not increase significantly, suggesting that the conductance did not significantly increase its value. However, the auroral electrojets were significantly enhanced. As a result, the ratio increases, implying an enhancement in the electric field. This inference of the enhanced electric field can be well supported by Hairston et al. (1999) for the 10 January 1997 event. They found that the polar cap potential rose up to $235 \mathrm{kV}$ during the density enhancement. The following MHD simulations (Lopez et al., 2004; Ober et al., 2006) also can reproduce the enhanced polar cap potential for the same event.

One important issue in the present study is that the error is usually large in the estimation of the solar wind propagation time from Wind to the center of the Earth by using the traditional ballistic method. We did not use this method; instead, we used a match of a disturbance on $|A L|$ or $A U$ with a solar wind disturbance. The reason we did that is that magnetometers at ground-based stations may observe magnetic disturbances when a solar wind density (or pressure) enhancement impacts the magnetosphere (e.g. Russell et al., 1994). For the 10 January 1997 event, there were several stations located at $\sim 74^{\circ}$ MLAT in the afternoon sector at 11:00 UT. These stations observed the northward magnetic disturbances driven by the density enhancement, which were the consequence of an enhancement in $A U$ (Kamide et al., 1998). Since each of the $A U$ index and $N_{p}$ has an enhancement, we can match both of them to estimate the propagation time. For the 11 February 1997 event, no magnetometer stations were located at $\sim 74^{\circ}$ MLAT in the afternoon sector during the period of the two density enhancements. The first density enhancement created an afternoon bright spot at $\sim 74^{\circ}$ MLAT, as shown in panel (c) of Fig. 1. If there were any stations under the bright spot, an enhancement would have been reflected in $A U$ in association with the bright spot. Fortunately, there were two peaks in $|A L|$. We thus can match these with the two peaks in the solar wind density.

We should also mention that Zesta et al. (2000) and Lyons et al. (2000) studied the same 10 January 1997 event and placed the solar wind density impact on the auroral iono-

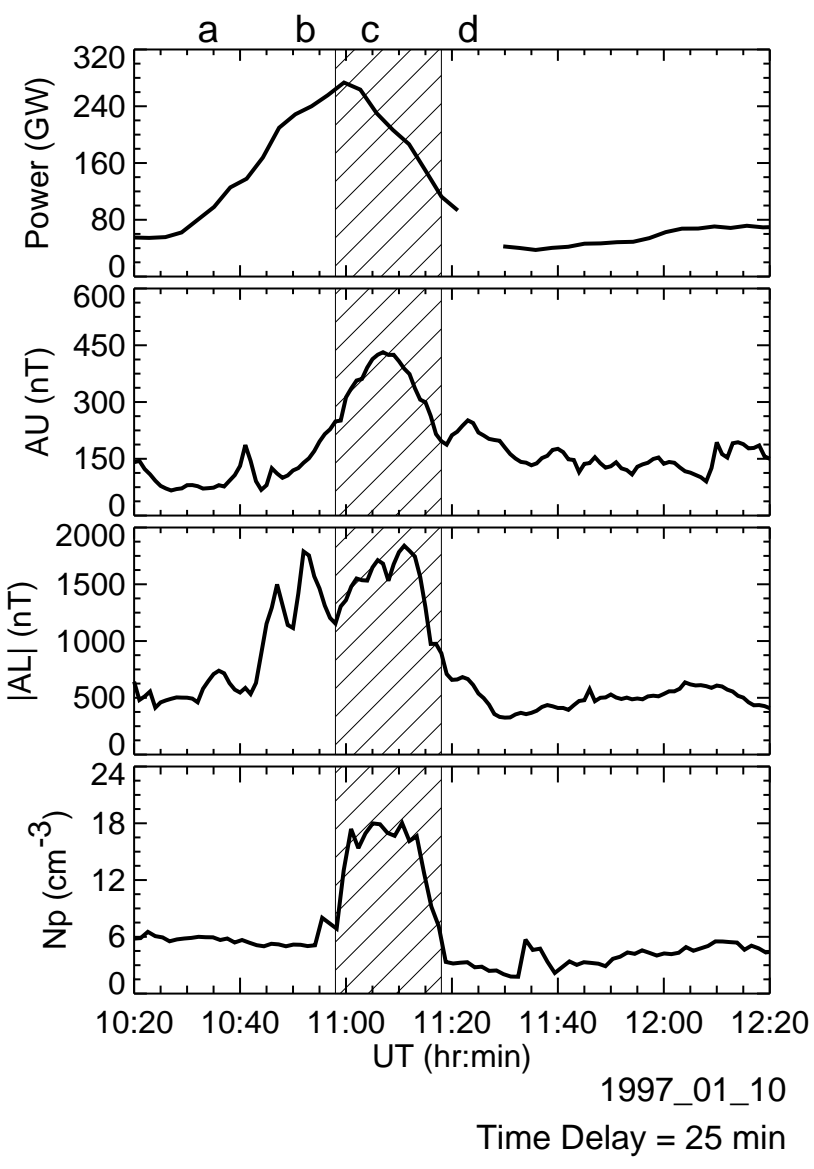

Fig. 4. The format is the same as Fig. 2 except for the 10 January 1997 event and the shifted time of $25 \mathrm{~min}$ in the solar wind density. The labels a-d on the top of the power panel are referred to the auroral images shown in Fig. 3.

sphere at 10:53 and 10:48 UT, respectively. If we take their average value of 10:50 UT as the average impact time of the solar wind density, we should have seen a significant shrinking of the polar cap by the density enhancement (Kamide et al., 1998; Boudouridis et al., 2003). However, we did not observe such a significant shrinking at this time (10:50 UT, from panel (b) in Fig. 3). The significant shrinking actually occurred at a later time (11:02 UT, from panel (c) in Fig. 3).

Another important issue is that the Polar UVI camera did not always observe the entire auroral oval in the nightside sector. We believe that this problem will not affect our conclusion as long as the field of view of the UVI camera remains unchanged during the events. The auroral images shown in Figs. 1 and 3 have demonstrated that the field of view is unchanged over the period of the events. On the other hand, our conclusion on the variations of the auroral power is presented and discussed in a relative scale.

In conclusion, the two events provide a good opportunity to study solar wind density effects on auroral electrojets and 
the integrated auroral power over the entire nightside region under the influence of substorms. The auroral power may not increase significantly in response to the density enhancement when a substorm occurred before the density enhancement impacts the magnetosphere. A possible interpretation is that the substorm had drained out a significant portion of the stored energy in the magnetotail; therefore, less precipitation energy was deposited into the auroral ionosphere by the density enhancement.

Acknowledgements. This work was supported in part by National Science Council grant NSC-94-2111-M-008-010 and in part by National Space Organization grant 95-NSPO(B)-SP-FA07-01 to National Central University. This work was also supported in part by Ministry of Education under the Aim for Top University program at NCU. We thank A. J. Lazarus, and R. P. Lepping for the use of Wind plasma and magnetometer data via the web page of NSSDC. We also thank G. K. Parks for the use of Polar UVI images.

Topical Editor R. Nakamura thanks A. Boudouridis and another anonymous referee for their help in evaluating this paper.

\section{References}

Boudouridis, A., Zesta, E., Lyons, L. R., Anderson, P. C., and Lummerzheim, D.: Effect of solar wind pressure pulses on the size and strength of the auroral oval, J. Geophys. Res., 108, 8012, doi:10.1029/2002JA009373, 2003.

Brittnacher, M., Elsen, R., Parks, G., Chen, L., Germany, G., and Spann, J.: A dayside auroral energy deposition case study using the polar ultraviolet imager, Geophys. Res. Lett., 24, 991-994, 1997.

Brittnacher, M., Wilber, M., Fillingim, M., Chua, D., Parks, G., Spann, J., and Germany, G.: Global auroral response to a solar wind pressure pulse, Adv. Space Res., 25, 1377-1385, 2000.

Burch, J. L.: Preconditions for the triggering of polar magnetic substorms by storm sudden commencements, J. Geophys. Res., 77, 5629-5632, 1972.

Caan, M. N., McPherron, R. L., and Russell, C. T.: Characteristics of the association between the interplanetary magnetic field and substorms, J. Geophys. Res., 82, 4837-4842, 1977.

Chua, D., Parks, G., Brittnacher, M., Peria, W., Germany, G., Spann, J., and Carlson, C.: Energy characteristics of auroral electron precipitation: A comparison of substorms and pressure pulse related auroral activity, J. Geophys. Res., 106, 5945-5956, 2001.

Craven, J. D., Frank, L. A., Russell, C. T., Smith, E. J., and Lepping, R. P.: Global auroral responses to magnetospheric compressions by shocks in the solar wind: Two case studies, Solar Wind-Magnetosphere Coupling, edited by: Kamide, Y. and Slavin, J. A., pp. 367, Terra Scientific, Tokyo, 1986.

Germany, G. A., Torr, M. R., Richards, P. G., and Torr, T. G.: The dependence of modeled OI 1356 and $\mathrm{N}_{2} \mathrm{LBH}$ auroral emissions on the neutral atmosphere, J. Geophys. Res., 95, 7725-7733, 1990.

Germany, G. A., Torr, M. R., Torr, T. G., and Richards, P. G.: Use of FUV auroral emissions as diagnostic indicators, J. Geophys. Res., 99, 383-388, 1994.

Gjerloev, J. W., Friel, M., Hoffman, R. A., Takahashi, K., Barnes, R., Meng, C., and Greenwald, R. A.: The global magnetometer network initiative: SuperMAG, Eos Trans. AGU, 85, Fall Meet. Suppl., Abstract SH41A-1079, 2004.

Hairston, M. R., Weimer, D. R., Heelis, R. A., and Rich, F.: Analysis of the ionospheric cross polar cap potential drop and electrostatic potential distribution patterns during the January 1997 CME event using DMSP data, J. Atmos. Sol. Terr. Phys., 61, 195-206, 1999.

Horwitz, J. L.: The substorm as an internal magnetospheric instability: Substorms and their characteristic time scales during intervals of steady interplanetary magnetic field, J. Geophys. Res., 90, 4164-4170, 1985.

Iijima, T.: Interplanetary and ground magnetic conditions preceding SSC-triggered substorms, Rep. Ionos. Space Res. Japan, 27, 205-208, 1973.

Kamide, Y., Shue, J.-H., Li, X., Lu, G., Brittnacher, M. J., Parks, G. K., and Reeves, G. D.: Internally and externally triggered substorms: A case study of the January 10, 1997 events, Substorm4, edited by: Kokubun, S. and Kamide, Y., pp. 305, Terra Sci., Tokyo, 1998.

Kokubun, S., McPherron, R. L., and Russell, C. T.: Triggering of substorms by solar wind discontinuities, J. Geophys. Res., 82, 74-86, 1977.

Lee, D.-Y., Lyons, L. R., Weygand, J. M., and Wang, C.-P.: Reasons why some solar wind changes do not trigger substorms, J. Geophys. Res. 112, A06240, doi:10.1029/2007JA012249, 2007.

Lepping, R. P., Acuna, M. H., Burlaga, L. F., et al.: The WIND magnetic field investigation, Space Sci. Rev., 71, 207-229, 1995.

Liou, K., Newell, P. T., Meng, C.-I., Wu, C.-C., and Lepping, R. P.: On the relationship between shock-induced polar magnetic bays and solar wind parameters, J. Geophys. Res., 109, A06306, doi:10.1029/2004JA010400, 2004.

Lopez, R. E., Wiltberger, M., Hernandez, S., and Lyon, J. G.: Solar wind density control of energy transfer to the magnetosphere, Geophys. Res. Lett., 31, L08804, doi:10.1029/2003GL018780, 2004.

Lukianova, R.: Magnetospheric response to sudden changes in solar wind dynamic pressure inferred from polar cap index, J. Geophys. Res., 108, 1428, doi:10.1029/2002JA009790, 2003.

Lyons, L. R.: A new theory for magnetospheric substorms, J. Geophys. Res., 100, 19069-19081, 1995.

Lyons, L. R., Zesta, E., Samson, J. C., and Reeves, G. D.: Auroral Disturbances During the January 10, 1997 Magnetic Storm, Geophys. Res. Lett., 27, 3237-3240, 2000.

Ober, D. M., Wilson, G. R., Maynard, N. C., Burke, W. J., and Siebert, K. D.: MHD simulation of the transpolar potential after a solar-wind density pulse, Geophys. Res. Lett., 539, L04106, doi:10.1029/2005GL024655, 2006.

Ogilvie, K. W., Chornay, D. J., Fritzenreiter, R. J., et al.: A comprehensive plasma instrument for the WIND spacecraft, Space Sci. Rev., 71, 55-77, 1995.

Ridley, A. J.: Estimations of the uncertainty in timing the relationship between magnetospheric and solar wind processes, J. Atmos. Sol. Terr. Phys., 62, 757-771, 2000.

Russell, C. T., Ginskey, M., and Petrinec, S. M.: Sudden impulses at low-latitude stations: Steady state response for northward interplanetary magnetic field, J. Geophys. Res., 99, 253-261, 1994.

Shue, J.-H. and Kamide, Y.: Effects of solar wind density on the westward electrojet, Substorm-4, edited by: Kokubun, S. and Kamide, Y., pp. 677, Terra Sci., Tokyo, 1998. 
Shue, J.-H. and Kamide, Y.: Effects of solar wind density on auroral electrojets, Geophys. Res. Lett., 28, 2181-2184, 2001.

Shue, J.-H. and Kamide, Y.: A systematic study of effects of solar wind density on auroral electrojets, Geophys. Res. Lett., 32, L14112, doi:10.1029/2005GL023197, 2005.

Shue, J.-H., Newell, P. T., Liou, K., and Meng, C.-I.: Solar wind density and velocity control of auroral brightness under normal interplanetary magnetic field conditions, J. Geophys. Res., 107, 1428, doi:10.1029/2001JA009138, 2002.

Strickland, D. J., Daniell, R. E., Jasperse, J. R., and Basu, B.: Transport-theoretic model for the electron-proton-hydrogen atom aurora, 2, Model results, J. Geophys. Res., 98, 2153321548, 1993.
Torr, M. R., Torr, D. G., Zukic, M., et al.: A far ultraviolet imager for the International Solar-Terrestrial Physics mission, Space Sci. Rev., 71, 329-383, 1995.

Zesta, E., Singer, H. J., Lummerzheim, D., et al.: The effect of the January 10, 1997 pressure pulse on the magnetosphereionosphere current system, Magnetospheric Current Systems, Geophys. Monogr. Ser., vol. 118, edited by: Ohtani, S.-I., Fujii, R., Hesse, M., and Lysak, R. L., pp. 217, AGU, Washington, D.C., 2000.

Zhou, X. and Tsurutani, B. T.: Interplanetary shock triggering of nightside geomagnetic activity: Substorms, pseudobreakups and quiescent events, J. Geophys. Res., 106, 18957-18967, 2001. 